\title{
Egyptian University Scientific Expedition to South-West Arabia
}

\author{
By Dr. S. A. Huzayyin
}

$\mathrm{B}$ ETWEEN April and October 1936 the Egyptian University of Cairo sent out a scientific expedition to Yaman and Hadhramaut. It consisted of four members, and was intended to carry out researches in the fields of geology, physiography, archæology, anthropology and entomology. The expedition covered a distance of some 2,500 kilometres and was able to carry out intensive researches at various localities both on the High Plateau of Yaman and in the interior of Hadhramaut. The material brought back has not been studied in detail as yet; but a preliminary note can be given here.

\section{GeOLOGY}

One of the expedition's main aims was to work out certain problems connected with the geological history of the southern borders of the Red Sea. We worked at a number of points along the lines of rifting both south and west of the Yaman Plateau, where the old crystalline rocks (schists and granites) of the base were exposed under later (secondary and tertiary) sediments and lavas. The successive horizons of the tertiary traps of the High Plateau were carefully examined and specimens collected. In north-east Yaman we worked chiefly on Jurassic limestones and Nubian sandstones, and a large collection of fossils was made from the successive zones of the former. The interior of Hadhramaut was found to have a relatively simple structure and to consist mostly of Eocene limestones on earlier unfossiliferous sandstones. We hope that new evidence from the lower part of the Eocene may throw useful light on the date of the trap volcanic series of tertiaries in south-west Arabia.

\section{PHYSIOGRAPHY}

Pleistocene geology proved to be quite interesting. We worked chiefly on the middle parts of the valleys, which were relatively independent of changes in base (sea) level. Two physiographic cycles were estab. lished, the first being by far the more pronounced. Valleys with sloping sides were first cut and then filled with coarse gravels which now rise (usually in two or more terraces) to some $30 \mathrm{~m}$. above the beds of the streams. During this stage there was a good deal of lateral wash and erosion in the middle parts of the valleys, and this erosion was probably responsible for the sloping sides of the V-shaped valleys. The gravels were examined at a large number of exposures, but unfortunately they produced only one or two specimens of pre-Chellean appearance.

The second physiographic cycle was associated first with the cutting of new steep-sided valleys emboitées in the older gravels, and then with the filling in of these new valleys with soft sediments of silt. Deposition was much more regular and there was very little lateral wash in the middle parts of the new valley-beds. The discharge during the depositional phase of the second cycle was much less than that during the depositional phase of the first cycle, as only soft silt could be carried to the middle courses of the streams. The two cycles were separated by a phase which was marked by extensive volcanic activity, especially in north-east Yaman, where the lava spreads always cover the old gravels and underlie the silts. The second cycle was followed by erosion, during which new torrential beds were cut into the silts (sometimes producing a series of erosional terraces). There has also been a still more recent (historical) outburst of volcanic activity (on a much more limited scale), the accompanying features of which are still noticeable in hot springs, etc.

We were able to associate the two physiographic cycles (or at least their depositional phases) with pluvial episodes. During Quaternary times this corner of Arabia seems to have had two major Pluvials separated by an Interpluvial. It was not possible to work out the stages of the first Pluvial, which was a prolonged one, and which must have had more than one sub-maximum (as shown by terraces); but there is presumptive evidence from one or two places that the second Pluvial may have had two sub. maxima separated by an Intrapluvial. In recent times there was a new wet phase (shown by archæological and other evidence), which we believe to have continued well into the Christian era (perhaps to the fifth century A.D.).

\section{ARCHEOLOGY}

The south-west plateau of Arabia proved to be singularly poor in prehistoric remains. Perhaps the great height (mainly above $1,500 \mathrm{~m}$.) and the unfavourable climatic conditions during pluvial episodes contributed to this. It is to be recalled that very fow remains have thus far been found at the high altitudes (above 6,000 ft.) of the opposite coasts of East Africa. We have carefully examined gravel exposures and have carried out experimental excavations at no fewer than fifteen caves and rock shelters in Yaman and Hadhramaut, but the results were largely negative. Surface specimens were looked for all along the route, but they were found only in very limited numbers and in particularly favourable localities; they belong typologically to Lower and Middle Palæolithic and rarely to the Upper Palæolithic. Whatever may have been the reasons, the scarcity of even surface finds shows that even if remains of prehistoric man may some day be forthcoming from this region, they will never be comparable in quantity with those from the African side. This reflects rather unfavourably on recent views put forward with regard to East Africa as a centre of cultural diffusion in Lower Palæolithic times.

Remains relating to the early historic phase of the area were, on the other hand, particularly abundant. Work and excavations at a number of places in Yaman and Hadhramaut have yielded fairly illuminating results. New light is thrown on relations between south-west Arabia on one hand and the Hellenistic East and Græco-Roman Egypt on the other, during the early centuries of the Christian era. 
More than a hundred new Sabaitic inscriptions were copied and photographed. At three sites in the Aden and Hadhramaut protectorate, particularly the ruins of Reiboun (near Mash-had) there is, on the other hand, contacts with East Africa. Here we found an industry of obsidian (with some flint) in definite association with pottery and with Sabaito-Himyaritic inscriptions, all found in shallow kitchen midden-like remains and amongst ruins of ancient buildings and habitations. Some of the characters were actually inscribed on the pottery both before and after baking. The obsidian industry includes practically all the types and sub-types of the so-called final Palæolithic and Neolithic cultures of East Africa-Wilton, Elmenteitan and Gumban. There are small nuclei, simple and retouched blades, truncated and notched ones, small backed knives, trapezoidal forms (in abundance), true lunates (less abundant), chisel-ended tools or pièces écaillées ('sinew-frayers' of Dr. L. S. B. Leakey), borers, medium-size and small burins (but not the micro-burin proper) and scrapers of various descriptions (nucleiform, round, at end of blade, etc.). Yet there can be no doubt about the SabaitoHimyarite date of this industry in south-west Arabia (the few centuries centring round the beginning of the Christian era).

Apart from inscriptions (on stone and on pottery) there are metal elements and beads of dating value. The pottery here is much more developed and varied than in East Africa, but this is to be expected in a country with more progressive civilization. One cannot argue from the evidence we have for the separa. tion of the obsidian industry from the rest of the datable remains which must all have belonged at least to one and the same culture phase*. If this be so, the dates assigned by Dr. Leakey and others to the so-called final Palæolithic and Neolithic industries of East Africa will have to be revised. It would be unreasonable to argue for a 'survival' into historic times of an obsidian and flint technique in south-west Arabia after it had been introduced from the African side at a final Palæolithic date. It would be rather in this latter region (East Africa), which produced no such highly progressive civilizations as we know from south-west Arabia, that we should expect such 'persistence'. Perhaps many of the Microlithic elements of industries in East Africa may ultimately prove to be of comparatively recent historic date (Christian era).

We have also discovered, at a number of rock shelters in the Middle Wadi Hadhramaut, rock draw. ings (both animals and men) of both naturalistic and schematic styles. The former were associated with Himyaritic inscriptions (mostly names and cartouches), while the latter were of much more recent appearance. At the base of some of the rock shelters we found a flake and blade industry of flint which we have reason to associate with the first series of drawings.

\section{Anthropology}

Anthropometrical measurements were made of 1,350 male individuals, of whom 800 were studied in Yaman and 550 in Hadhramaut. More than 400 individuals were photographed full face and profile. The individuals are representative of the great majority of the tribes inhabiting the area, and useful light may be expected to be shed both on local distribution of anthropological features and types and on similarities and connexions with neighbouring areas in Asia and
Africa. Already interesting links are being worked out with Iran and the west Deccan. Local differences have also been worked out within both Yaman and Hadhramaut. The population of the northern part of the Yaman plateau is essentially mesocephalic, though it also shows certain features due to mixture. South Yaman, on the other hand, has broader heads. There is also a number of Jewish colonies in Yaman from whom representative groups were measured. In Hadhramaut we have a markedly brachycephalic type (very dominant, especially in the interior) and a mesocephalic one (especially on the coast). The broad heads of Hadhramaut show interesting anthropometrical features, and the roundness of their heads is primarily due to shortness (flattening of the back) rather than to width. Armenoid affinities among the broad heads of south Arabia are already known from previous observation and measure. ments (Bertram Thomas, etc.). The High Plateau of Yaman is practically free from prognathism, which becomes more and more marked as we go eastwards into Hadhramaut. We have reason to believe that this feature was not the result of crossing with Negroids from Africa, but represents an element brought from farther East. Special attention, however, has been paid to cases and areas of metisation between Negroid and Arab types, especially in coastal regions. Some peoples of the coastal plains of west Yaman have been shown to have marked affinities with the Negroids of Africa, who, however, do not seem to have affected the High Plateau to any appreciable extent. Certain parts of the Hadhramaut coast are equally mixed, and even in the interior there are colonies of imported elements (for example, Negro soldier-slaves, IndoChinese and Chinese elements as slaves and wives brought back by enterprising merchants of Hadhramaut, etc.).

\section{ENTOMOLOGY}

Between five and six thousand specimens have been collected, and a large number of these were actually set in the field. They represent fauna from all the altitudes we have passed through (from sea-level to $3,500 \mathrm{~m}$.). The identification of our specimens will inevitably be a long process, but it is hoped that fresh light may be thrown on the question of migration between adjacent parts of Africa and Asia in these regions. One of the chief topics we worked upon was the question of locust breeding-grounds and migrations, and already some useful results have been achieved in this direction.

In addition to these topics, members of the expedition carried out side-line investigations, such as the taking of a meteorological record during the journey (with as few breaks as possible), the collection of plants and small animals in localities which have not been visited before and of fishes and aquatic fauna from all streams and springs along the way, as well as the recording of observations on the general geography and ethnography of the lands and peoples in the areas visited.

* Should there be any chance of such a separation, however, the only possibility would be that at a posterior date poorer tribes took shelter among the Sabaito-Himyarite ruins and left their obsidian industry thoroughly mixed with earlier remains. In that case the lithic industry would be still more recent than the Sabasn phase. There can be no possibility of the Sabaito-Himyarites having chosen for sites of their cities places where earlier obsidian and flintusing tribes left their kitchen midden and rubbish heaps. 